\title{
Effects of intradialytic progressive resistance training on muscle strength, physical capacity and quality of life in end-stage renal disease patients
}

Efeitos do treinamento de resistência progressiva intradialítica na força muscular, capacidade física e qualidade de vida em pacientes com doença renal em estágio terminal

Efectos del entrenamiento de resistencia progresivo intradiálisis sobre la fuerza muscular, la capacidad física y la calidad de vida en pacientes con enfermedad renal en etapa terminal

Received: 07/13/2021 | Reviewed: 07/17/2021 | Accept: 07/20/2021 | Published: 07/29/2021

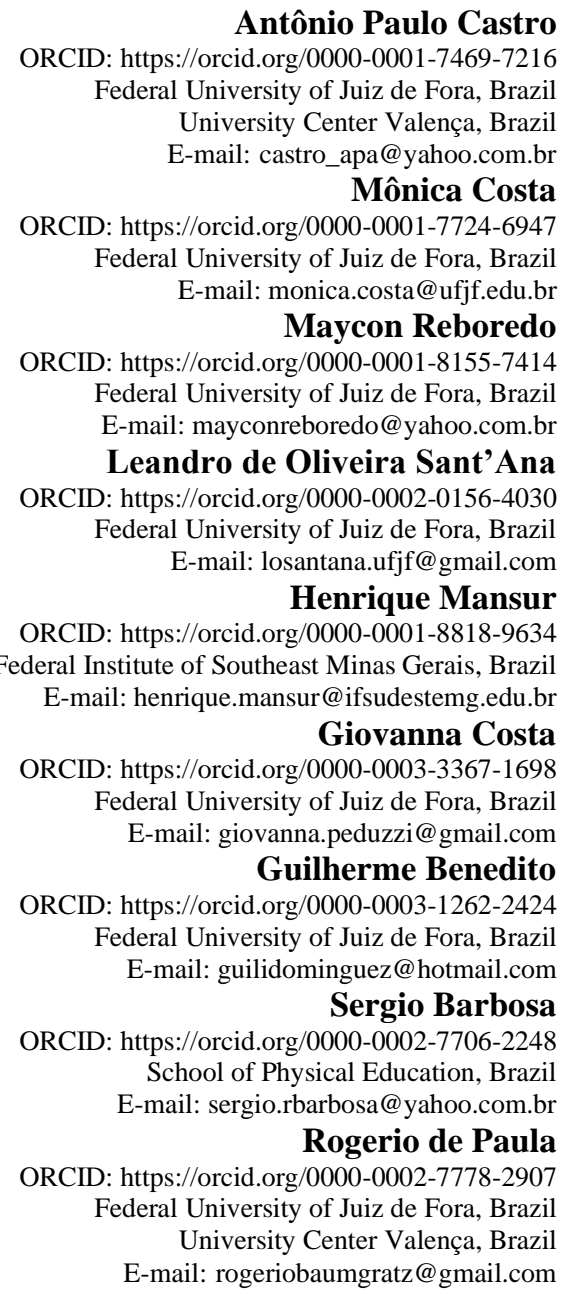

\begin{abstract}
Objective: This study aimed to investigate the effects of moderate- to high-intensity intradialytic progressive resistance training (IPRT) on muscle strength (MS), physical capacity (PC), and quality of life (QoL) in end-stage renal disease patients. Methods: Twenty-seven sedentary hemodialysis patients $(55.5 \pm 10.6$ years $)$ were divided into a resistance training group (RTG, $n=15)$ and a control group $(\mathrm{CG}, \mathrm{n}=12)$. Patients of RTG were submitted to IPRT, three times per week for 12 weeks. The Borg's scale was used for exercise prescription. Muscle strength was measured using hand grip dynamometry (MS). The sit-to-stand (STS) test and usual walking speed (UWS) test were performed to measure the physical capacity, and the SF-36 questionnaire to evaluate the quality of life (QoL). All patients were evaluated at baseline and after 12 weeks. Results: Moderate- to high-intensity IPRT significantly increased the MS ( $p=0.001$, effect size $(\mathrm{ES})=0.98)$, the physical capacity evaluated by the STS $(\mathrm{p}=0.002, \mathrm{ES}=0.85)$ and UWS $(\mathrm{p}=0.014, \mathrm{ES}=1.11)$, and all domains of SF-36 questionnaire $(\mathrm{p}<0.05)$. On the other hand, in the CG these variables did not change significantly.
\end{abstract}


The protocol was well tolerated and was not associated with significant clinical complications. Conclusion: Twelve weeks of moderate- to high-intensity IPRT in HD patients was safe and improved MS, PC, and QoL.

Keywords: Renal failure; Hemodialysis; Strength training; Physical capacity; Exercise; Quality of life.

\section{Resumo}

Objetivo: Este estudo teve como objetivo investigar os efeitos do treinamento resistido progressivo intradialítico de intensidade moderada a alta (IPRT) na força muscular (MS), capacidade física (PC) e qualidade de vida (QV) em pacientes renais em estágio terminal. Métodos: Vinte e sete pacientes sedentários em hemodiálise $(55,5 \pm 10,6$ anos $)$ foram divididos em um grupo de treinamento resistido $(\mathrm{RTG}, \mathrm{n}=15)$ e um grupo controle $(\mathrm{GC}, \mathrm{n}=12)$. Os pacientes do RTG foram submetidos ao IPRT, três vezes por semana, durante 12 semanas. A escala de Borg foi usada para prescrição de exercícios. A força muscular foi medida por meio da dinamometria de preensão manual (MS). Os testes sentar para levantar (STS) e velocidade usual de caminhada (UWS) foram realizados para mensurar a capacidade física, e o questionário SF-36 para avaliar a qualidade de vida (QV). Todos os pacientes foram avaliados no início e após 12 semanas. Resultados: O IPRT de intensidade moderada a alta aumentou significativamente o MS ( $\mathrm{p}=0,001$, tamanho do efeito $(\mathrm{ES})=0,98)$, a capacidade física avaliada pelo STS $(\mathrm{p}=0,002, \mathrm{ES}=0,85)$ e UWS $(\mathrm{p}=0,014, \mathrm{ES}=1,11)$, e todos os domínios do questionário SF-36 ( p <0,05). Por outro lado, no GC essas variáveis não se alteraram significativamente. $\mathrm{O}$ protocolo foi bem tolerado e não foi associado a complicações clínicas significativas Conclusão: Doze semanas de IPRT de moderada a alta intensidade em pacientes em HD foram seguras e melhoraram a EM, CP e QV.

Palavras-chave: Insuficiência renal; Hemodiálise; Treinamento de força; Capacidade física; Exercício; Qualidade de vida.

\section{Resumen}

Objetivo: Este estudio tuvo como objetivo investigar los efectos del entrenamiento de resistencia progresiva intradiálisis (IPRT) de intensidad moderada a alta sobre la fuerza muscular (EM), la capacidad física (CP) y la calidad de vida (CdV) en pacientes con enfermedad renal en etapa terminal. Métodos: Veintisiete pacientes sedentarios en hemodiálisis $(55,5$ $\pm 10,6$ años) se dividieron en un grupo de entrenamiento de resistencia (RTG, $\mathrm{n}=15)$ y un grupo de control (GC, $\mathrm{n}=$ 12). Los pacientes de RTG se sometieron a IPRT, tres veces por semana durante 12 semanas. Se utilizó la escala de Borg para la prescripción de ejercicios. La fuerza muscular se midió mediante dinamometría de agarre manual (MS). Se realizaron el test sit-to-stand (STS) y el test de la velocidad de marcha habitual (UWS) para medir la capacidad física, y el cuestionario SF-36 para evaluar la calidad de vida (QoL). Todos los pacientes fueron evaluados al inicio del estudio y después de 12 semanas. Resultados: IPRT de intensidad moderada a alta aumentó significativamente la MS ( $p=0,001$, tamaño del efecto $(E S)=0,98)$, la capacidad física evaluada por la STS $(p=0,002$, ES $=0,85)$ y UWS $(p=0,014$, ES $=1,11)$ y todos los dominios del cuestionario SF-36 ( $\mathrm{p}<0,05)$. Por otro lado, en el GC estas variables no cambiaron significativamente. El protocolo fue bien tolerado y no se asoció con complicaciones clínicas significativas. Conclusión: Doce semanas de IPRT de intensidad moderada a alta en pacientes en HD fueron seguras y mejoraron la EM la CP y la calidad de vida.

Palabras clave: Insuficiencia renal; Hemodiálises; Entrenamiento de fuerza; Capacidad física; Ejercicio; Calidad de vida.

\section{Introduction}

Patients with end-stage renal disease undergoing hemodialysis (HD), have a sedentary lifestyle that is associated with increased rates of morbidity and mortality, particularly due to cardiovascular events (Vanholder et al. 2005; Eckhard et al. 2009). In this population, cardiovascular diseases, endocrine and metabolic disorders, malnutrition, inflammation, bone mineral disease and neuromuscular dysfunction, contribute to lower levels of muscle strength (MS), physical capacity (PC), and exercise tolerance (Junyent et al. 2010; Odden et al. 2004; Beddhu et al. 2009) when compared to healthy individuals or patients in earlystage chronic kidney diseases (CKD) (Lin and Curhan, 2008; Johansen et al. 2010). These factors contribute to a vicious cycle that is associated with sedentary lifestyle, increased risk of falls, hospitalization, and decreased quality of life (QoL) (Cheema et al. 2014; Li et al. 2016; Seckinger et al. 2016). In this context, exercise training has been recommended as a therapeutic tool in an attempting to attenuate the deleterious effects of CKD on strength, muscle mass and PC in this population.

To date, most studies in this population have used cardiorespiratory training (Cheema et al. 2005). However, in patients undergoing HD treatment, the effects of this training modality on physical capacity remains controversial (Zhao et al. 2019). 
Regarding to muscle strength, an independent marker of mortality risk, the effectiveness of cardiorespiratory training appears to be insignificant (Ruiz et al. 2008)

On the other hand, based on physiological and mechanical aspects, resistance training seems to be more effective in improving muscle strength (Fry, 2004; Kraemer and Ratamess, 2004) Although resistance training can increase physical capacity evaluated by walking speed and sit-and-stand test, as well as muscle strength, the results in QoL still remain controversial (Zhao et al. 2019).

The aim of this study was to evaluate the effects of 12 weeks of supervised progressive intradialytic resistance training on MS, PC, and QoL in patients on HD treatment.

\section{Methodology}

\section{Participants}

The study sample included patients older than 18 years who were on chronic HD treatment for at least three months in the Nephrology Unit at the Kidney Disease Treatment Center, Brazil. Exclusion criteria were: inadequacy of dialysis $(\mathrm{Kt} / \mathrm{V})$ $<1.2$, severe heart, lung or liver diseases; acute systemic infection; severe renal osteodystrophy; severe neurological disorders; cancer; poorly controlled hypertension (systolic blood pressure $[\mathrm{SBP}] \geq 200 \mathrm{mmHg}$ and/or diastolic blood pressure [DBP] $\geq 120$ $\mathrm{mmHg}$ ); poorly controlled diabetes mellitus (fasting blood glucose $>11.1 \mathrm{mmol} / \mathrm{L} ; \geq 200 \mathrm{mg} / \mathrm{dL}$ ); and previous musculoskeletal disorders. The study was performed in accordance with the principles of the Declaration of Helsinki and approved by the Research Ethics Committee of Federal University of Juiz de Fora (protocol $n^{\circ}$. 375.003). All patients signed an informed consent term.

Twenty-seven HD patients were included in this study and allocated into two groups: resistance training group (RTG, $\mathrm{n}=15)$ and control group (CG, $\mathrm{n}=12)$. The groups were matched for physical capacity (Figure 1).

Figure 1: flowchart showing the flow of patients through the study and data analysis.

\begin{tabular}{|l|}
\hline 13 patients were ineligible: \\
not meeting inclusion criteria \\
5 patients were excluded: \\
2 deaths \\
2 hemodialysis shift to \\
peritoneal dialysis \\
1 severe heart failure \\
\hline
\end{tabular}

\section{8 patients recruited}

\begin{tabular}{|l|}
\hline \multicolumn{1}{|c|}{$\begin{array}{c}\text { Resistance training group } \\
(\mathbf{n}=\mathbf{1 7})\end{array}$} \\
\hline 2 patients were excluded: \\
1 drop out \\
1 received kidney transplant \\
\hline
\end{tabular}

Twelve-week follow-up

\begin{tabular}{|l|}
\hline \multicolumn{1}{|c|}{$\begin{array}{c}\text { Control group } \\
(\mathbf{n}=13)\end{array}$} \\
\hline 1 \\
\hline 1 patient was excluded: \\
1 received kidney transplant \\
\hline
\end{tabular}

Resistance training group $(n=15)$

\section{7 patients completed the follow-up}

Control group $(\mathbf{n}=12)$

Source: Authors. 


\section{Study design}

Patients included in the RTG were submitted to intradialytic progressive resistance training, and patients allocated to the control group remained in usual dialysis treatment. Before and after 12 weeks of the protocol, the patients were submitted to muscle strength, physical capacity and quality of life evaluation. In order to ascertain the safety of exercise training, the patients were submitted to cardiac evaluation and a symptom-limited ergometric test using a ramp protocol on a non-dialysis day (Fletcher et al. 2013).

\section{Measurements}

Muscle strength was evaluated by hand grip strength test using a Saehan@, hydraulic dynamometer (Saehan Corporation 973, Yangdeok-dong, Masan 630-728, Korea). Patients were asked to stay in the seated position with their arms in adduction and their elbows flexed on a 90-degree angle without touching the armrest. Measurements were performed in the contralateral arteriovenous fistula arm or in dominant arm in the case of a long-term dialysis catheter. The mean of three attempts was considered the value of MS maximum.

To evaluate PC the sit-to-stand (STS) 30-s and usual walking speed (UWS) tests were performed. In the STS, patients were instructed to stand up from a seated position and sit back down, with their arms folded across the chest, on a standard 44 $\mathrm{cm}$ straight-back chair with no armrests. They were instructed to perform as many repetitions as possible within $30 \mathrm{~s}$. In the UWS test, the patients were instructed to walk a distance of 4.57 meters on a flat and obstacle-free surface at their UWS. The test was repeated three times, and the mean of all the series was considered as the result.

The QoL was determined using the Medical Outcomes Study 36-item Short-form Health Survey (SF-36), which is a generic validated questionnaire translated into Portuguese (Ciconelli et al. 1999). The SF-36 questionnaire comprises 36 items that assess the individual self-perception of eight domains: physical functioning, role physical, pain, general health, vitality, social functioning, role emotional, and mental health. A score is obtained for each domain on a scale ranging from 0 (worst possible status) to 100 (best possible status).

The demographic and clinical data were obtained from the medical records.

\section{Resistance training program}

Patients of the RTG were submitted to moderate- to high-intensity intradialytic progressive resistance training (IPRT), three times per week for 12 weeks, and patients of the control group remained in usual dialysis treatment. Supervised training sessions lasted 50 minutes and were performed during the first two hours of the HD session by using dumbbells and weighted ankle-cuffs. The IPRT protocol included exercises for the main muscle groups (dorsal muscles: unilateral upright rowing; pectoral muscles: chest press; deltoid muscles: shoulder press; quadriceps muscles: knee extension; hamstring muscles: knee flexion; gastrocnemius muscle: plantar flexion in the upright position; triceps brachii muscle: triceps extension; biceps brachii muscle: biceps curl).

In the first week of training (familiarization phase), only one set of 10 to 15 repetitions was performed for each exercise. In the second week, the number of sets was increased to two sets of 10 to 15 repetitions. From the third week onwards, the protocol was changed to three sets of 10 to 15 repetitions. At all stages of the protocol, the rating of perceived exertion (RPE) proposed by Borg ${ }^{18}$ was used to control the exertion intensity. The RPE should remain between 15 and 17 (i.e., equivalent to "hard" and "very hard," respectively) and at the end of each set and each exercise, the patient was asked about the RPE. If the level of exertion was outside the proposed range, the load was adjusted and was either increased or decreased by approximately $5 \%$. To control the exercise intensity, for patients who performed the maximum number of programmed repetitions (i.e., 15 
repetitions) in the three sets, the load was adjusted by approximately 5\% in the following session. At every stage of the protocol, the patients were allowed a resting interval of 90 to 120 seconds between the sets and exercises. Lastly, to avoid early muscle fatigue, the exercises for different body segments were performed in an alternating manner (Kraemer and Ratamess, 2004).

Before starting the IPRT session, blood pressure and resting heart rate were obtained, and capillary blood glucose was measured in patients with diabetes. For security issue, the training session only was performed if SBP was between 110 and 160 $\mathrm{mmHg}$ and/or, DBP was between 60 and $100 \mathrm{mmHg}$ and the resting heart rate was between 50 and $100 \mathrm{bpm}$. In patients with diabetes, capillary blood glucose should be between 5.55 and $13.87 \mathrm{mmol} / \mathrm{L}$ (100 and $250 \mathrm{mg} / \mathrm{dL}$ ). The criteria for exercise interruption included intense physical exhaustion, chest pain, dizziness, or pre-syncope.

\section{Statistical analysis}

Descriptive analysis was performed using mean, standard deviation, and median (interquartile interval) values, as well as absolute and relative values when appropriate. The differences between the groups before and after intervention were analyzed using Student's $t$-test for independent samples, Wilcoxon test, two-way analysis of variance for repeated measures, and Pearson's $\chi^{2}$ test, according to data distribution. The power of the sample size was determined using OpenEpi, based on the effect of postintervention exercise-training on MS. Considering the sample size and an alpha error of 0.05 , the power $(1-\beta)$ achieved was 0.82 for MS max. The results were statistically significant when $\mathrm{p}<0.05$. All analyses were performed using $\mathrm{R} 3.3 .2$ for Windows $@$ (R Core Team, Vienna, Austria).

\section{Results}

Table 1 presents the demographic and clinical characteristics of both groups. There were no significant differences between RTG and CG regarding to these characteristics (Table 1).

Table 1: Demographic and clinical characteristics of the assessed population.

\begin{tabular}{|c|c|c|c|c|}
\hline Variable & $\begin{array}{c}\text { Total } \\
(n=27)\end{array}$ & $\begin{array}{c}\text { CG } \\
(n=12)\end{array}$ & $\begin{array}{c}\text { RTG } \\
(\mathbf{n}=15)\end{array}$ & $\mathbf{p}$ \\
\hline Gender $(\mathrm{M} / \mathrm{F})$ & $\begin{array}{c}23 / 4 \\
(85.2 \% / 14.8 \%)\end{array}$ & $\begin{array}{c}10 / 2 \\
(83.4 \% / 16.4 \%)\end{array}$ & $\begin{array}{c}13 / 2 \\
(86.6 \% / 13.4 \%)\end{array}$ & 0.148 \\
\hline Age (years) & $55.5(10.6)$ & $53.8(13.4)$ & $56.8(7.9)$ & 0.507 \\
\hline Time on HD (months) & $\begin{array}{c}50.0 \\
(21.5-136.5)\end{array}$ & $\begin{array}{c}65.0 \\
(21.5-141.5)\end{array}$ & $\begin{array}{c}36.0 \\
(13.5-102.0)\end{array}$ & 0.267 \\
\hline \multicolumn{5}{|l|}{ Etiology of CKD } \\
\hline Hypertensive nephrosclerosis & $11(40.8 \%)$ & $3(25.0 \%)$ & $8(53.4 \%)$ & \\
\hline Glomerulonephritis & $5(18.5 \%)$ & $3(25.0 \%)$ & $2(13.4 \%)$ & \\
\hline Diabetic kidney disease & $4(14.8)$ & $3(25.0 \%)$ & $1(6.7 \%)$ & \\
\hline Polycystic kidney disease & $2(7.4 \%)$ & $1(8.4 \%)$ & $1(6.7 \%)$ & \\
\hline Others/uncertain & $5(18.5 \%)$ & $2(16.6 \%)$ & $3(19.8 \%)$ & \\
\hline
\end{tabular}

Source: Authors.

In 15 patients in the RTG who completed 12 weeks of intervention (36 sessions), the adherence rate was $96.5 \pm 2.9 \%$. Pain and hypertension were the main reasons for the suspension of some training sessions. After the 522 training sessions, no complications, intercurrences or adverse events that required out-of-routine medical assistance were observed. 
The MS and PC results are presented in Table 2. After the protocol, RTG showed a significant improvement in MS and PC compared to CG. For MS the effect size was of 0.98 (95\% confidence interval (CI) 11.06; 69.73), for the number of repetitions in the STT the effect size was of 0.85 (95\% CI 14.30; 19.00), and for UWS the effect size was of 1.01 (95\% CI 1.11; 1.36), after the intervention.

Table 2: Pre- and post-intervention results of the handgrip strength, sit-to-stand, and usual walking speed tests in both groups.

\begin{tabular}{lccccccc}
\hline \multicolumn{1}{c}{ Variable } & \multicolumn{3}{c}{ Control group $(\mathbf{n = 1 2})$} & \multicolumn{3}{c}{ Resistance training group (n=15) } \\
\hline & Baseline & 12 weeks & $\Delta$ & Baseline & 12 weeks & $\Delta$ & $\mathrm{p}^{\mathrm{a}}$ \\
\cline { 2 - 7 } Handgrip (kgf) & $29.5(11.8)$ & $27.9(11.7)$ & $-1.5(3.3)$ & $27.5(11.9)$ & $33.2(11.5)$ & $6.1(2.9)$ & 0.001 \\
30sSTS (repetitions) & $11.4(3.9)$ & $12.4(4.6)$ & $1.0(2.3)$ & $12.4(3.9)$ & $16.7(4.7)$ & $4.3(2.3)$ & 0.002 \\
Usual walking speed (m/s) & $1.05(0.19)$ & $0.93(0.32)$ & -0.12 & $1.10(0.27)$ & $1.24(0.24)$ & $(0.14$ & 0.014 \\
& & & $(0.2)$ & & & & $(0.3)$ \\
\hline
\end{tabular}

Results expressed as mean (SD). ${ }^{\text {a }}$ Comparison of $\Delta$ between the groups at baseline and 12 weeks later. 30sSTS: 30-s sit-to-stand test. Source: Authors.

At the baseline, QoL was similar in both groups (Figure 2A). Twelve weeks after the intervention, RTG exhibited a significant increase in scores for all the dimensions of QoL (Figure 2D). In addition, the scores of the eight dimensions decreased in the $\mathrm{CG}$, at the end of the follow-up period (Figure 2C), reaching a statistical significance for social functioning (87.5 vs 62.5; $\mathrm{p}=0.023)$ and physical limitations $(75.0$ vs 50.0; $\mathrm{p}=0.009)$.

Figure 2: Effects of intradialytic progressive resistance training on each domain of quality of life. A: CG vs RTG at baseline; B: CG vs RTG 12 weeks later; C: CG at baseline vs 12 weeks later; D: RTG at baseline vs 12 weeks later. * p $<0,05$.
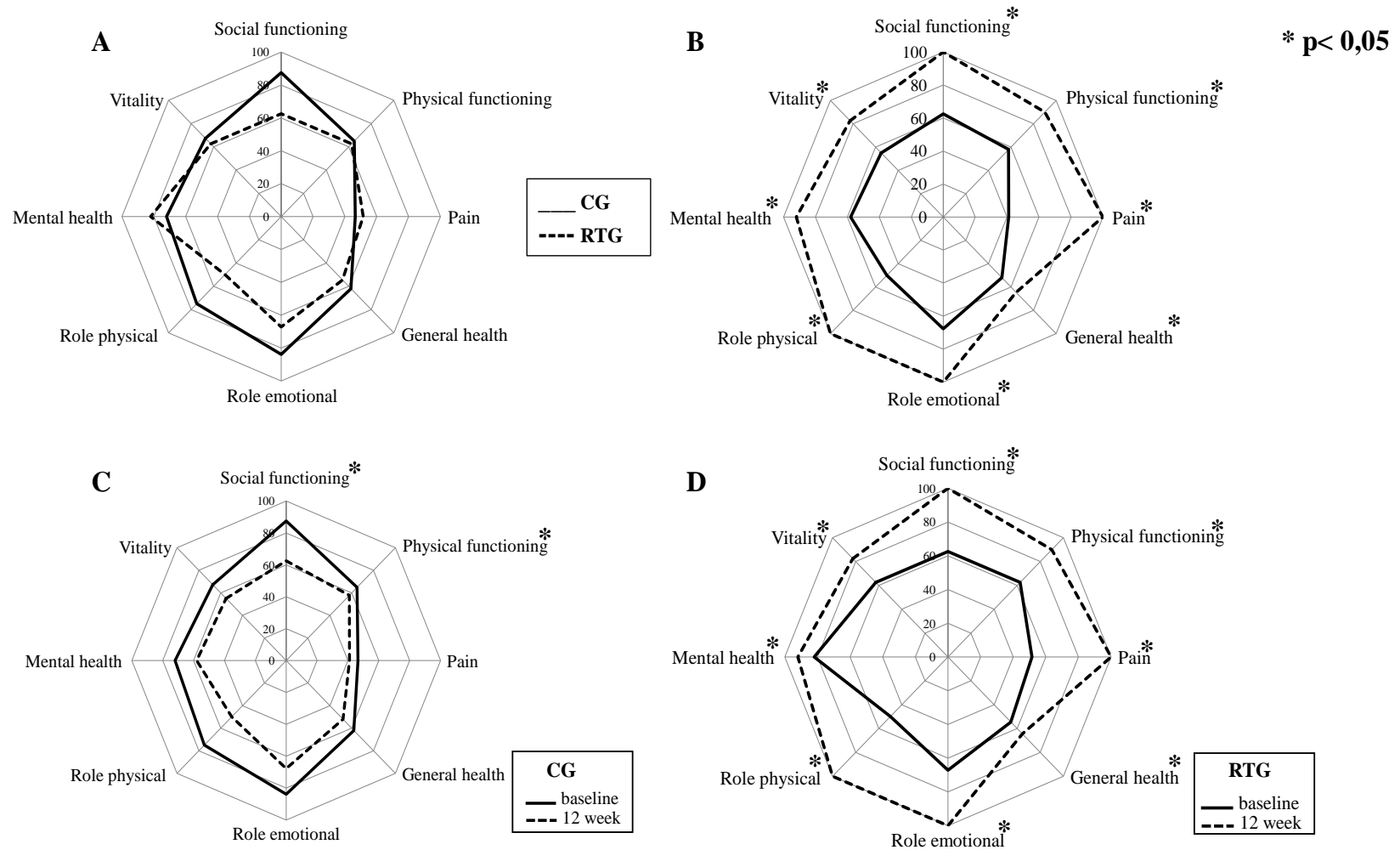

Source: Authors. 


\section{Discussion}

In this study it was demonstrated that moderate- to high-intensity IPRT was safe and increased MS and PC as well as improved QoL of patients with ESRD on HD.

After the exercising intervention, in the RTG the increase of approximately $20 \%$ in MS confirms the findings of previous studies and is within the range reported in the literature (Headley et al. 2002; Cheema et al. 2007; Chen et al. 2010; Molsted et al. 2013; Kirkman et al. 2014; Martin-Alemany et al. 2014) In one of the first studies that investigated the effects of RT on MS and PC in HD patients, Headley et al. (2002) observed an increase of approximately 13\% in the MS of the knee extensor muscles after 12 weeks of intervention. Cheema et al. (2007), in the Progressive Exercise for Anabolism in Kidney Disease study, reported an overall increase of $20 \%$ in MS of the knee extensor, hip abductor, and triceps brachii muscles. Similarly, Chen et al. (2010), Molsted et al. (2013), and Kirkman et al. (2014) reported an increase of 45\%, 46\%, and 60\%, respectively, in the MS of the knee extensor muscles. The wide variation in findings reported in the literature is probably due to the differences in the age of the participants, training frequency and intensity, number and type of exercises, and resistance method adopted (machines, free weights, or elastic bands). The results obtained in the present study were very similar to those using machines or sophisticated equipment even though only dumbbells and weighted ankle-cuffs were used. The main determining factors for these results probably were the gradual increase of load and the rigorous control of intensity, which were individually adapted for each participant, as recommended by Fry (2004).

Another significant finding observed in the present study was the effect of RT in the UWS, an important marker of PC. According to the study of Kutner et al. (2002), patients with UWS $<0.6 \mathrm{~m} / \mathrm{s}$ exhibit a higher risk of mortality when compared to those with UWS $\geq 0.6 \mathrm{~m} / \mathrm{s}$. In these patients, a reduction of $0.1 \mathrm{~m} / \mathrm{s}$ in UWS increased the risk of mortality by $17 \%$. In the present study, the UWS increased from $0.9 \mathrm{~m} / \mathrm{s}$ to $1.4 \mathrm{~m} / \mathrm{s}$, a much higher level than that reported in other studies (Chen et al. 2010; Kirkman et al. 2014; Bullani et al. 2011). Thus, the increase in MS and UWS as well as the improvement in the performance in the STS observed in RTG suggest that IPRT is a potentially effective therapeutic strategy for prevention and reversal of the functional decline exhibited by patients on HD.

Moreover, reduced PC in patients with CKD has been associated with decreased QoL (kalantar et al. 2001; Lee et al. 2015; Li et al. 2016; Lyasere et al. 2016)). A multicenter study involving 2,507 patients with CKD, aged between 19 and 98 years, who had a low QoL, indicated a mortality rate of $34.7 \%$ in elderly and $15.8 \%$ in younger patients (Seckinger et al. 2016). The risk of mortality increases proportionally with the decrease in the perception of QoL mainly in the physical health component (Tsai et al. 2010). In the present study, a significant increase in scores for all dimensions of QoL was observed, which is in line with the result of previous studies (Cheema et al. 2007; Chen et al. 2010; Song and Sohng, 2012; Molsted et al. 2013; Rosa et al. 2018).

A concern regarding IPRT is the risk of acute complications such as cardiac arrhythmia, intradialytic hypotension or hypertension, hematoma and loss of venous access (Himmelfarb, 2005). However, in the present study, after 522 IPRT sessions, no complications requiring out-of-routine clinical assistance were observed. It could be speculated that the risk of complications may have been partly attenuated by previous cardiological evaluation, adoption of strict criteria for pre-exercise blood pressure levels, and ongoing physical trainer supervision of all training sessions.

A limitation of the present study is the non-randomization of the groups. However, based on the methodological characteristics, the study was a pragmatic, real-life clinical trial that reflected the reality of HD centers. Another limitation is that we cannot generalize our results to any HD population due to the number of patients included and because it is a single center protocol. On the other hand, the strong points of this study were the cardiological evaluation before enrolling the patients in the 
training protocol as well as the selection of an easy-to-execute training protocol under professional supervision, which ensured patients safety and promoted a higher than usual adherence rate.

\section{Conclusion}

In patients with ESRD on HD, IPRT increased MS, PC, and QoL. In addition, moderate- to high-intensity training was well-tolerated and was not associated with significant clinical complications. However, further studies are needed in order to provide more answers on the subject and thus be able to add new mandatory intervention parameters with CKD.

\section{Clinical Messages}

- Moderate- to high-intensity intradialytic progressive resistance training can improve muscle strength, physical capacity, and quality of life.

- The results were achieved in a safe way using low-cost equipment, which may facilitate the implementation and management of the protocol in CKD treatment centers.

- Further studies using low-cost equipment are required to investigate the effects of moderate-to high-intensity IPRT on parameters associated with nutritional status, muscle hypertrophy, bone mineral density, blood pressure, and inflammation status.

\section{Conflict of Interest}

The authors declare no conflict of interest, financial or otherwise.

\section{Acknowledgments}

Acknowledgment for the financing of financial support proposed by the Foundation for Research Support of the State of Minas Gerais (FAPEMIG). Federal University of Juiz de Fora, Minas Gerais, Brazil. For the scholarship to the researcher and Ph.D. student in Physical Education Leandro de Oliveira Sant'Ana.

\section{References}

Beddhu, S., et al. Physical activity and mortality in chronic kidney disease (NHANES III). Clin J Am Soc Nephrol 2009; 4: 1901-1906. 2009/10/13. 10.2215/CJN.01970309.

Borg, G. Psychophysical bases of perceived exertion. Medicine and Science in Sports and Exercise. 1982;14(5):377-381.

Bullani, R., al. Effect of intradialytic resistance band exercise on physical function in patients on maintenance hemodialysis: a pilot study. J Ren Nutr 2011; 21: 61-65. 2011/01/05. 10.1053/j.jrn.2010.10.011.

Ciconelli, R. M., et al. Tradução para língua portuguesa e validação do questionário genérico de avaliação de qualidade de vida SF-36 (Brasil SF-36). Revista Brasileira de Reumatologia. 1999 Mai/Jun;39:143-150.

Cheema, B. S., \& Singh, M. A. Exercise training in patients receiving maintenance hemodialysis: a systematic review of clinical trials. Am J Nephrol 2005; 25 : 352-364. 2005/08/10. 10.1159/000087184.

Cheema, B., et al. Progressive exercise for anabolism in kidney disease (PEAK): a randomized, controlled trial of resistance training during hemodialysis. $J$ Am Soc Nephrol 2007; 18: 1594-1601. 2007/04/06. 10.1681/ASN.2006121329.

Cheema, B. S., et al. Effect of progressive resistance training on measures of skeletal muscle hypertrophy, muscular strength and health-related quality of life in patients with chronic kidney disease: a systematic review and meta-analysis. Sports Med 2014; 44: 1125-1138. 2014/04/04. 10.1007/s40279-014-0176-8.

Chen, J. L., et al. Effect of intra-dialytic, low-intensity strength training on functional capacity in adult haemodialysis patients: a randomized pilot trial. Nephrol Dial Transplant 2010; 25: 1936-1943. 2010/01/27. 10.1093/ndt/gfp739.

Eckardt, K. U., et al. Definition and classification of CKD: the debate should be about patient prognosis--a position statement from KDOQI and KDIGO. Am J Kidney Dis 2009; 53: 915-920. 2009/05/02. 10.1053/j.ajkd.2009.04.001. 
Fletcher, G. F., et al. Exercise standards for testing and training: a scientific statement from the American Heart Association. Circulation 2013; 128: 873-934. 2013/07/24. 10.1161/CIR.0b013e31829b5b44.

Fry, A. C. The role of resistance exercise intensity on muscle fibre adaptations. Sports Med 2004; 34: 663-679. 2004/09/01. 10.2165/00007256-20043410000004.

Headley, S., et al. Resistance training improves strength and functional measures in patients with end-stage renal disease. American Journal of Kidney Diseases 2002; 40: 355-364. 10.1053/ajkd.2002.34520.

Himmelfarb, J. Hemodialysis Complications. American Journal of Kidney Diseases 2005; 45: 1122-1131. 10.1053/j.ajkd.2005.02.031.

Iyasere, O. U., et al. Quality of Life and Physical Function in Older Patients on Dialysis: A Comparison of Assisted Peritoneal Dialysis with Hemodialysis. Clin J Am Soc Nephrol 2016; 11: 423-430. 2015/12/30. 10.2215/CJN.01050115.

Johansen, K. L., et al. Low level of self-reported physical activity in ambulatory patients new to dialysis. Kidney Int 2010; 78: 1164-1170. 2010/09/03. 10.1038/ki.2010.312.

Junyent, M., et al. Predicting cardiovascular disease morbidity and mortality in chronic kidney disease in Spain. The rationale and design of NEFRONA: a prospective, multicenter, observational cohort study. BMC Nephrol 2010; 11: 14. 2010/07/09. 10.1186/1471-2369-11-14

Kalantar-Zadeh, K., et al. Association among SF36 quality of life measures and nutrition, hospitalization, and mortality in hemodialysis. J Am Soc Nephrol. 2001 Dec;12(12):2797-2806.

Kraemer, W. J., \& Ratamess, N. A. Fundamentals of resistance training: progression and exercise prescription. Med Sci Sports Exerc 2004; 36: 674-688. 2004/04/06

Kirkman, D. L., et al. Anabolic exercise in haemodialysis patients: a randomised controlled pilot study. J Cachexia Sarcopenia Muscle 2014 ; 5: 199-207. 2014/04/09. 10.1007/s13539-014-0140-3.

Kutner, N. G., \& Jassal, S. V. Quality of life and rehabilitation of elderly dialysis patients. Semin Dial. 2002 Mar/Abr;2(15):107-112. 10.1046/j.1525139x.2002.00034.x

Lee, J. E., et al. Factors Influencing Quality of Life in Adult End-Stage Renal Disease Patients Undergoing Hemodialysis. J Nurs Res 2015; 23: 181-188. 2015/05/20. 10.1097/jnr.0000000000000087.

Li, Y. N., et al. Association between quality of life and anxiety, depression, physical activity and physical performance in maintenance hemodialysis patients. Chronic Dis Transl Med 2016; 2: 110-119. 2017/10/25. 10.1016/j.cdtm.2016.09.004.

Lin, J., \& Curhan, G. C. Kidney function decline and physical function in women. Nephrol Dial Transplant 2008; 23: 2827-2833. 2008/04/10. $10.1093 / \mathrm{ndt} / \mathrm{gfn} 121$

Martin-Alemany, G., et al. The effects of resistance exercise and oral nutritional supplementation during hemodialysis on indicators of nutritional status and quality of life. Nephrol Dial Transplant 2016; 31: 1712-1720. 2016/08/12. 10.1093/ndt/gfw297.

Molsted, S., et al. Increased rate of force development and neuromuscular activity after high-load resistance training in patients undergoing dialysis. Nephrology (Carlton) 2013; 18: 770-776. 2013/08/02. 10.1111/nep.12145.

Molsted, S., et al. The effects of high-load strength training with protein- or nonprotein-containing nutritional supplementation in patients undergoing dialysis. J Ren Nutr 2013; 23: 132-140. 2012/09/11. 10.1053/j.jrn.2012.06.007.

Rosa, C., et al. Effect of continuous progressive resistance training during hemodialysis on body composition, physical function and quality of life in end-stage renal disease patients: a randomized controlled trial. Clin Rehabil 2018; 32: 899-908. 2018/03/06. 10.1177/0269215518760696.

Ruiz, J. R., et al. Association between muscular strength and mortality in men: prospective cohort study. BMJ 2008; 337: a439. 2008/07/04. 10.1136/bmj.a439.

Seckinger, J., et al. Morbidity, mortality and quality of life in the ageing haemodialysis population: results from the ELDERLY study. Clin Kidney J 2016; 9: 839-848. 2016/12/21. 10.1093/ckj/sfw087

Song, W. J., \& Sohng, K. Y. Effects of progressive resistance training on body composition, physical fitness and quality of life of patients on hemodialysis. $J$ Korean Acad Nurs 2012; 42: 947-956. 2013/02/05. 10.4040/jkan.2012.42.7.947.

Tsai, Y. C., et al. Quality of life predicts risks of end-stage renal disease and mortality in patients with chronic kidney disease. Nephrol Dial Transplant 2010; 25: 1621-1626. 2009/12/29. 10.1093/ndt/gfp671.

Vanholder, R., et al. Chronic kidney disease as cause of cardiovascular morbidity and mortalityNephrol Dial Transplant 2005; 20: 1048-1056. 2005/04/09. $10.1093 / \mathrm{ndt} / \mathrm{gfh} 813$.

Zhao, Q. G., et al. Exercise interventions on patients with end-stage renal disease: a systematic review. Clin Rehabil 2019; 33: 147-156. 2019/02/23. $10.1177 / 0269215518817083$ 